\title{
Human RCAN3 gene expression and cell growth in endothelial cells
}

\author{
SILVIA CANAIDER ${ }^{1}$, MARINA VETTRAINO $^{1}$, LUCY V. NORLING $^{2}$, ENZO SPISNI $^{3}$, \\ FEDERICA FACCHIN $^{1}$, DIANNE COOPER ${ }^{2}$ and MAURO PERRETTI ${ }^{2}$ \\ ${ }^{1}$ Department of Histology, Embryology and Applied Biology, University of Bologna, Via Belmeloro 8, Bologna, Italy; \\ ${ }^{2}$ William Harvey Research Institute, Queen Mary University of London, Bart's and The London Medical School, \\ Charterhouse Square, London, EC1M 6BQ, UK; ${ }^{3}$ Department of Experimental Biology, \\ University of Bologna, via Selmi 3, 40126 Bologna, Italy
}

Received May 28, 2010; Accepted July 20, 2010

DOI: $10.3892 /$ ijmm_00000542

\begin{abstract}
Regulator of calcineurin 3 (RCAN3) belongs to the human $R C A N$ gene family, which also includes $R C A N 1$ and RCAN2. All three members interact with and inhibit calcineurin. Based on this effect, several studies have demonstrated a role for RCAN1 and RCAN2 on inflammation, using human umbilical vein endothelial cells (HUVECs) as a model. RCAN1 and 2 are strongly induced by vascular endothelial growth factor (VEGF), inhibit cell proliferation and downregulate many pro-inflammatory and pro-angiogenic genes. The present work is the first study to investigate the role of RCAN3 on inflammation in HUVECs. RCAN3 isoforms have been characterized and quantified in HUVECs; only those with the same frame are expressed and show a peculiar expression pattern. RCAN3 inhibits HUVEC proliferation both basally and under VEGF or phorbol 12-myristate 13acetate-stimulated conditions, however it does not modulate gene expression of the chosen inflammatory genes. Results indicate an interesting role for RCAN3 in modulating HUVEC proliferation, independently from the inflammatory and angiogenic processes.
\end{abstract}

\section{Introduction}

Regulator of calcineurin 3 (RCAN3) gene (also known as DSCR1L2 (1), MCIP3, CALP3) belongs to the human regulator of calcineurin $[R C A N(2)$ gene family which also includes RCAN1 (also known as DSCRI (3), MCIP1, CALP1, ADAPT78) and RCAN2 (also known as ZAKI-4 (4), DSCR1L1, $M C I P 2, C A L P 2)]$. Due to the large number of human RCAN3 mRNA isoforms, the specific nomenclature proposed in a

Correspondence to: Dr Silvia Canaider, Department of Histology, Embryology and Applied Biology, University of Bologna, Via Belmeloro 8, 40126 Bologna, Italy

E-mail: silvia.canaider@unibo.it

Key words: regulator of calcineurin 3, proliferation, inflammation, human umbilical vein endothelial cells, vascular endothelial growth factor, phorbol 12-myristate 13-acetate recent paper (5) will be used here. The human RCAN3 gene (1p36.11) encodes for a 241 amino acid predicted protein $(27.5 \mathrm{kDa})$, is expressed in many human tissues $(1,5)$ and is the most recent member of the human RCAN gene family, appearing only in vertebrates (6). RCAN-like proteins are conserved from yeast to humans and share a highly conserved consensus motif (FLISPP motif) comprising the signature of the family (1). RCAN3 has recently been demonstrated to interact with calcineurin (7) as well as RCAN1 and RCAN2 gene products $(8,9)$. Calcineurin $(\mathrm{Cn})$ is a $\mathrm{Ca}^{2+} /$ calmodulinactivated serine/threonine phosphatase that is involved in the transcriptional activation of many target genes. Cn activation upon an intracellular $\mathrm{Ca}^{2+}$ increase leads to phosphorylation of its substrates, including the NFAT transcription factors that translocate to the nucleus, where, in cooperation with other transcription factors, they induce gene expression of target genes. In particular, calcineurin inhibitor RCAN (RCAN CIC) motif has been demonstrated to bind Cn (10). Cn signaling plays a part in many physiological processes including cardiac hypertrophy $(11,12)$, T-cell activation (13), skeletal myocyte differentiation and fiber-type switching (14), synaptic plasticity and neurotransmission $(15,16)$.

Several studies have been carried out to clarify the role of RCAN1 in inflammation and angiogenesis by using human umbilical vein endothelial cells (HUVECs) as a model. The first study using HUVECs (17) analyzed a human cDNA chip containing 7,267 human genes to identify those genes induced by vascular endothelial growth factor (VEGF), one of the most important factors that stimulates angiogenesis and vascular permeability. RCAN1 appeared as one of the most highly induced genes. This result was confirmed in a separate study (18). Yao and collegues (19) hypothesized that this upregulation is part of an endogenous feedback inhibitory circuit for angiogenesis by regulating the Cn-NFAT signaling pathway. Another study used microarray analyses (20) to confirm a marked up-regulation of RCAN1 after VEGF treatment and demonstrated that constitutive expression of RCAN1 in endothelial cells inhibits nuclear localization of NF-ATc and tube formation in HUVECs, attenuates proliferation of HUVECs, blocks matrix neo-vascularization and down-regulates many pro-inflammatory and pro-angiogenic genes like E-selectin and VCAM-1. A related study determined that transient expression of RCAN1 attenuated 
inflammatory marker genes such as tissue factor (TF), Eselectin, and cyclooxygenase-2 (Cox-2) in HUVECs activated with VEGF (21).

The role of RCAN2 in HUVECs under VEGF treatment has also been investigated (22). VEGF potently up-regulates RCAN2, whose constitutive overexpression prevented the nuclear translocation of NF-ATc1, underscoring its role as a $\mathrm{Cn}$ inhibitor. Additionally, RCAN2-transduced cells inhibited VEGF-induced endothelial cell migration, proliferation, and tube formation, demonstrating that RCAN2 is constitutively expressed in endothelial cells and acts in a similar manner to RCAN1.

The majority of studies to date have focused on RCAN1, although a role for both RCAN1 and RCAN2 in VEGF-Cn mediated angiogenesis and inflammation in endothelial cells has been identified. The function of RCAN3 however, has not yet been investigated in endothelial cells, although it has been demonstrated to interact with $\mathrm{Cn}$ resulting in inhibition of $\mathrm{Cn}$ activity towards NFAT transcription factors and downregulation of NFAT-dependent cytokine gene expression in activated human Jurkat T cells (7).

The aim of our work is to study the basic biology of RCAN3 in HUVECs. Initial experiments were conducted to determine whether $R C A N 3$, and/or its isoforms, is expressed in HUVECs. Then, an siRNA able to decrease RCAN3 expression was designed to investigate its role in HUVECs both basally and under stimulated conditions.

\section{Materials and methods}

Reverse transcription-polymerase chain reaction (RT-PCR). Standard reverse transcription conditions were, $2 \mu \mathrm{g}$ total RNA, Moloney murine leukemia virus reverse-transcriptase (Promega, Madison, WI), used with companion buffer, $400 \mathrm{U}$, oligo dT-15 $2.5 \mu \mathrm{M}$, random hexamers $2 \mu \mathrm{M}$, dNTPs $500 \mu \mathrm{M}$ each. RT reaction was performed in a final volume of $50 \mu 1$ for $60 \mathrm{~min}$ at $37^{\circ} \mathrm{C}$. Standard PCR conditions for amplifications were, $25 \mu 1$ final volume, primers $0.2 \mu \mathrm{M}$ each, BioMix Red (Bioline, Taunton, MA). Initial denaturation was $2 \mathrm{~min} 30 \mathrm{sec}$ at $94^{\circ} \mathrm{C}$, 30 cycles of $60 \mathrm{sec}$ at $94^{\circ} \mathrm{C}, 45 \mathrm{sec}$ at the annealing temperature (Ta) of $61^{\circ} \mathrm{C}, 60 \mathrm{sec}$ at $72^{\circ} \mathrm{C}$, final extension, $7 \mathrm{~min}$ at $72^{\circ} \mathrm{C}$. Deviations from these conditions are given below when appropriate. Primers used to clone $R C A N 3, R C A N 3-2,5$, $R C A N 3-2,3,4 b, 5, R C A N 3-2,3,5$ and $R C A N 3-2,4,5$ are those previously described (5), while other primers are listed in Table I. DNA sequencing and sequence analysis were performed as decribed in Facchin et al (5).

Cell culture. HUVECs were isolated from recently collected umbilical cords. Cells were grown in Medium 199 (Sigma, St. Louis, MO) supplemented with $20 \%$ human serum (HS) (Lonza, Basel, Switzerland), 2 mM L-glutamine (Sigma), and antibiotics (penicillin $100 \mathrm{U} / \mathrm{ml}$ and streptomycin $100 \mathrm{mg} / \mathrm{ml}$, Sigma), as previously described (23). Cells were maintained at $37^{\circ} \mathrm{C}$ in $5 \% \mathrm{CO}_{2}$ on $0.2 \%$ gelatin-coated plates (Sigma) or flasks and used for experiments between the 2nd and 6th passage. Cell viability was assessed by using the trypan-blue dye exclusion assay and daily microscopic observation. When pro-inflammatory treatments were performed, they consisted of: VEGF (R\&D Systems, Oxon, UK), $30 \mathrm{ng} / \mathrm{ml}$, phorbol
Table I. Primer list.

\begin{tabular}{|c|c|c|}
\hline No. & Primer sequence $5 \rightarrow 3$ & Gene \\
\hline 1 & $\begin{array}{l}\text { TATTTTGCACAGGT } \\
\text { GCAGATGTCC (F)a }\end{array}$ & RCAN3 \\
\hline 2 & $\begin{array}{l}\text { CAGAGTCTCACCT } \\
\text { ATGCTGTTCG }(\mathrm{R})^{\mathrm{b}}\end{array}$ & RCAN3 \\
\hline 3 & $\begin{array}{l}\text { GTGCTAGCTCCAGC } \\
\text { TCAGCTACCT }(\mathrm{F})\end{array}$ & RCAN3-1a,2,3,4 \\
\hline 4 & $\begin{array}{l}\text { AGATAGGACTTGT } \\
\text { CCCGCACTTCGC (R) }\end{array}$ & RCAN3-1a,2,3,4 \\
\hline 5 & $\begin{array}{l}\text { TGTATGTATGAGTG } \\
\text { TGGGATTTGAC }(\mathrm{F})\end{array}$ & COX-2 \\
\hline 6 & $\begin{array}{l}\text { GATCATCTCTGCCTG } \\
\text { AGTATCTTTG }(\mathrm{R})\end{array}$ & $\mathrm{COX}-2$ \\
\hline 7 & $\begin{array}{l}\text { GAAACCTCTGACAG } \\
\text { AAGAAGCCAAG (F) }\end{array}$ & E-selectin \\
\hline 8 & $\begin{array}{l}\text { GTGACTGCAAACCA } \\
\text { GGCTTCCATGCTC (R) }\end{array}$ & E-selectin \\
\hline 9 & $\begin{array}{l}\text { CTTTGGATAATGTT } \\
\text { TGCAGCTTCTC (F) }\end{array}$ & VCAM-1 \\
\hline 10 & $\begin{array}{l}\text { CTCTTGGTTTCCAG } \\
\text { GGACTTCCTG }(\mathrm{R})\end{array}$ & VCAM-1 \\
\hline 11 & $\begin{array}{l}\text { CTGCTGCTGAGATG } \\
\text { AATGAAACAGTA }(\mathrm{F})\end{array}$ & GM-CSF \\
\hline 12 & $\begin{array}{l}\text { GGTGATAATCTGGG } \\
\text { TTGCACAGGAAG (R) }\end{array}$ & GM-CSF \\
\hline 13 & $\begin{array}{l}\text { GTTTCAGTGTTCAA } \\
\text { GCAGTGATTCC (F) }\end{array}$ & $\mathrm{TF}$ \\
\hline 14 & $\begin{array}{l}\text { CGACCTGGTTAATC) } \\
\text { CTTAAGTGCG (R) }\end{array}$ & $\mathrm{TF}$ \\
\hline
\end{tabular}

${ }^{\mathrm{a}} \mathrm{F}$, forward primer; ${ }^{\mathrm{b}} \mathrm{R}$, reverse primer.

12-myristate 13-acetate (PMA) (Sigma), $200 \mathrm{ng} / \mathrm{ml}$ and ionomycine (IO) (Sigma), $5 \mu \mathrm{M}$. When appropriate, cells were harvested in TriReagent (Ambion, Austin, TX), and RNA was chloroform extracted.

Small interfering RNA transfection assay. RCAN3 small interfering RNA (RCAN3-siRNA) and the negative scrambled control siRNA (SCRAM-siRNA) were purchased from Sigma. RCAN3-siRNA was designed by Sigma to inhibit all RCAN3 isoforms, including the reference gene RCAN3, our main gene of interest.

HUVECs were seeded in $35-\mathrm{mm}^{2}$ dishes (six-well culture dish) two days before transfection at a density of $2 \times 10^{5}$ cells/ well in complete media. Transfections were performed with non-targeting, SCRAM-siRNA or a target-specific RCAN3siRNA. For each dish $80 \mathrm{pmol}$ of siRNA duplex were used and the assay was performed according to the manufacturer's guidelines (Santa Cruz Biotechnology, Santa Cruz, CA). After $24 \mathrm{~h}$ media were replaced with complete fresh media. Knockdown of RCAN3 mRNA expression was monitored by quantitative relative RT-PCR after 24, 48 and $72 \mathrm{~h}$. In each case at least a 50\% decrease of RCAN3 mRNA was observed and all experiments were then performed between 24 and $48 \mathrm{~h}$ depending on methods. 
Alamar Blue assay for cell quantification. RCAN3-siRNA transfected and non-transfected cells were trypsinized and centrifuged at room temperature and the cell pellet was resuspended in medium with $2 \% \mathrm{HS}$. In order to eliminate differences due to medium colour, the experiment was performed using culture media filtered with sterile activated charcoal to remove phenol red. Cells were then seeded in duplicate in a 96-well plate (200 $\mu 1$ per well), and incubated at $37^{\circ} \mathrm{C}$. After an initial 4-h period to allow cell attachment, cells were treated with VEGF $(30 \mathrm{ng} / \mathrm{ml})$ or PMA $(200 \mathrm{ng} / \mathrm{ml})$, then $20 \mu \mathrm{l}$ Alamar Blue (AB, Biosource, Camarillo, CA) solution was directly added to the medium (final concentration of $10 \%)$. As a negative control $\mathrm{AB}$ was added to the medium without cells. The plate was further incubated for $24 \mathrm{~h}$ at $37^{\circ} \mathrm{C}$. The absorbance of wells was read at 540 and $620 \mathrm{~nm}$ with a standard spectrophotometer for the subsequent four days. The number of viable cells correlating with the magnitude of dye reduction is expressed as percentage of $\mathrm{AB}$ reduction according to the manufacturer's protocol (24).

The optimal seeding density and culture period resulted in 10,000 cells/well and the $\mathrm{AB}$ values at $72 \mathrm{~h}$ after treatment. Three independent experiments were performed.

Quantitative relative $R T-P C R$ and gel imaging. Relative quantification of $R C A N 3$ mRNA isoforms or inflammatory genes in HUVECs was performed by quantitative relative RT-PCR. 32 microglobulin (B2M) housekeeping cDNA was used for normalization of investigated genes. PCR experiments for quantitative relative analysis were performed in standard conditions except that 25 cycles for B2M cDNA, 40 for RCAN3 isoform cDNA and 30 for inflammatory gene cDNA were determined at the maximum distance from the PCR reaction plateau. Inflammatory genes amplified were COX-2, E-selectin, vascular cell adhesion molecule-1 (VCAM-1), granulocyte/macrophage colony-stimulating factor (GM-CSF) and tissue factor (TF) genes.

To standardize all PCR reactions for quantitative relative analysis, we performed a single mix with BioMix Red, water and cDNA. The mix was dispensed into samples and a different primer pair was added to each one. Each PCR reaction was performed in duplicate and electrophoresed in the same $1 \%$ agarose Tris acetate EDTA-ethylene diamine tetraacetic acid (TAE) gel. Mass Ruler Express HR Forward and Reverse DNA Ladder (Fermentas, Hanover, MA) was used as a quantitative reference. After separation, the gel was stained in TAE buffer containing ethidium bromide $(0.5 \mathrm{mg} / \mathrm{ml})$ and detected under ultraviolet light in 'unsaturated pixel' modality with the Gel Doc 2000 Imaging System. Digital images were analyzed by Quantity One software (Bio-Rad, Hercules, CA, USA), using the 'Volume Rect Tool' function to acquire intensity of pixel data for each band and subtract gel image total background. Intensity values of the PCR product bands were calculated in comparison with a regression line with correlation coefficient $\geq 0.98$ generated from measurements of at least four marker bands with different concentration values.

Statistical analysis. Assessable replicate data points for $B 2 M$, RCAN3 isoforms and inflammatory genes were successfully obtained. The mean for each replicate data point (expressed as PCR product mass in $\mathrm{ng}$ ) normalized with correspondent $B 2 M$ values (gene/B2M product mass ratios) was determined.
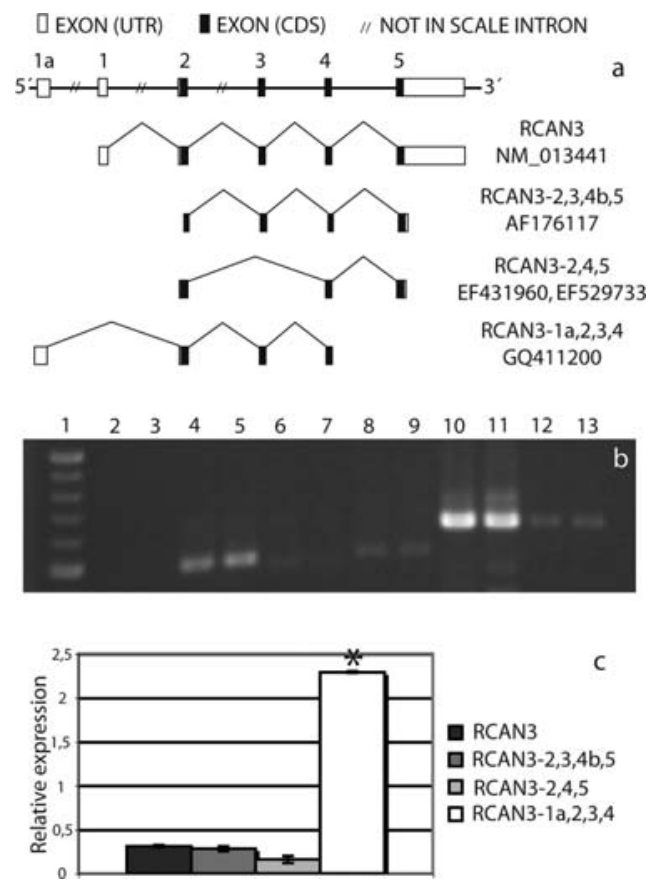

Figure 1. Relative quantification of RCAN3 isoforms expressed in HUVECs. a) Schematic representation of the four RCAN3 gene isoforms expressed in HUVECs illustrating their exon-intron organization. The diagram shows the longest sequences available to date (see GenBank accession numbers in the figure). b) Representative agarose 1\% gel reveals expressed RCAN3 isoforms in HUVECs. Lanes 1, marker Gene Ruler; 2-3, Marker Mass Ruler (out of the frame); 4-5, RCAN3; 6-7, RCAN3-2,3,4b,5; 8-9, RCAN3-2,4,5; 10-11, RCAN3-1a,2,3,4, 12-13 B2M. c) Graph shows results of one experiment representative of 3 independent experiments with the same trend. RCAN3$1 \mathrm{a}, 2,3,4$ isoform is the most abundantly expressed $\left({ }^{*} \mathrm{P}<0.05\right)$ compared to the other known isoforms of RCAN3 in HUVECs. Data are normalized to $\mathrm{B} 2 \mathrm{M}$ housekeeping gene.

Statistical analysis on normalized values was performed using JMP software, version 5 (SAS Institute, Cary, NC, USA). The Two-sample t-test, used to evaluate the differences across two groups, was used for all assays proposed here. Values of $\mathrm{P}<0.05$ were considered statistically significant.

\section{Results and Discussion}

RCAN3-1a2,3,4 cDNA cloning. After a bioinformatic analysis, RT-PCR (using primers 3 and 4) was performed on human prostate cDNA to obtain for the first time a new spliced RCAN3 isoform, termed RCAN-1a,2,3,4 cDNA (deposited in GenBank under accession no. GQ411200). RCAN-1a,2,3,4 cDNA was in HUVEC extracts and the same pair of primers were applied. Sequence analysis of PCR products revealed the existence of a new alternative non-coding exon 1 (Fig. 1a), indicating that the new identified spliced isoform $R C A N$ $1 a, 2,3,4$ and the RCAN3 reference isoform code for the same protein. The meaning of alternative isoforms differing in $5^{\prime}$ UTR non-coding exons has to be linked to the regulation of expression of the specific isoform, in different tissues as well as in different cell conditions (25). We believe this is an intriguing observation that will be followed-up in future studies.

Amplification of RCAN3 isoforms expressed in HUVECs and their relative quantification. Numerous studies have addressed the anti-inflammatory nature of RCAN1 in HUVECs 


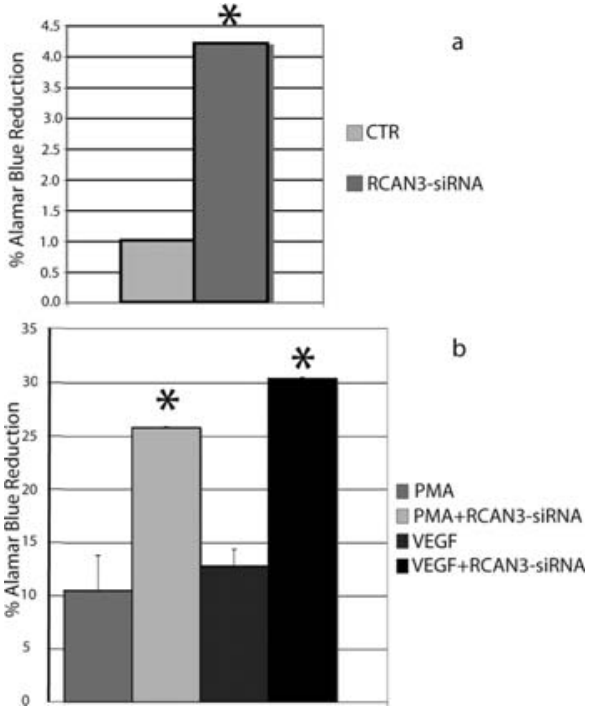

Figure 2. Role of RCAN3 on HUVEC proliferation. a) Proliferation of HUVECs under basal conditions. RCAN3-siRNA transfected HUVECs compared to control HUVECs, monitored at $72 \mathrm{~h}$. Data are average of fold increase of 3 independent experiments. b) Proliferation of stimulated HUVECs. HUVECs were stimulated with VEGF $(30 \mathrm{ng} / \mathrm{ml})$ or PMA $(200 \mathrm{ng} / \mathrm{ml})$ and transfected or not with RCAN3-siRNA, and proliferation monitored over $72 \mathrm{~h}$ Data are average of duplicate samples of one representative experiment of 2 independent experiments with the same trend $\left({ }^{*} \mathrm{P}<0.05\right)$.

model, with a few studies confirming the same role for RCAN2. Therefore in this study we investigated the presence of the third member, RCAN3, in the HUVEC model and began to determine its possible role in the inflammation process.

First we verified whether the five $R C A N 3$ isoforms identified to date, $R C A N 3, R C A N 3-2,5, R C A N 3-2,3,4 b, 5$, $R C A N 3-2,3,5$ and $R C A N 3-2,4,5$ (5) and a new one identified here for the first time, $R C A N 3-1 a, 2,3,4$, were expressed in HUVECs by RT-PCR. Only $R C A N 3, R C A N 3-2,3,4 b, 5$ (which lacks 30 nucleotides at the begining of exon 4 ), RCAN3-2,4,5 (which lacks exon 3) and RCAN3-1a,2,3,4 (which has an alternative non-coding exon 1 compared with RCAN3) isoforms are expressed (Fig. 1a). It is worth noting that all expressed isoforms are those which maintain the same frame, differing only in some amino acids, leading us to the hypothesis, they all share a common function in HUVECs driven by the conserved amino acid sequence.

Results showed that the RCAN3-1a,2,3,4 isoform was significantly $(\mathrm{p}<0.05)$ the most expressed isoform compared to the others in HUVECs. RCAN3-1a,2,3,4 isoform showed a mean 6.8-fold increase in expression compared to the RCAN3 isoform, while there was no significant quantitative difference between the other expressed isoforms (Fig. 1).

To date, in a representative panel of 7 tissues (heart, brain, small intestine, lung, testis, prostate, peripheral blood leukocytes), the most expressed isoform is RCAN3 (5). It is noteworthy that $R C A N 3-1 a, 2,3,4$ and RCAN3 differ only in the first alternative non-coding exon, leading to the same protein. This means that the significant difference of expression in HUVECs is cell-specific and located in the 5' regulative untranslated region of the gene.
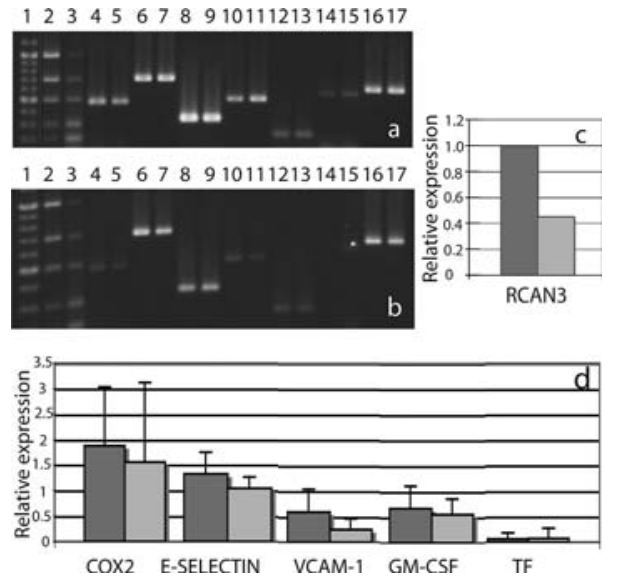

Figure 3. RCAN3 knockdown effect on inflammatory gene expression in HUVECs under basal conditions. In a) and b) two representative agarose $1 \%$ gels showing samples in duplicate of a RT-PCR (control in a, RCAN3siRNA in b). Lanes 1, marker gene ruler; 2-3, marker mass ruler; 4-5, RCAN3; 6-7, COX-2; 8-9, E-selectin; 10-11, VCAM-1; 12-13, GM-CSF; 14-15, TF; 16-17, B2M. c) RCAN3-siRNA (light grey) decrease RCAN3 expression by at least $55 \%$ in all experiments performed compared with control (dark grey) $(\mathrm{P}>0.05)$. d) RCAN3-siRNA (light grey) did not significantly alter $(\mathrm{P}>0.05)$ the expression of selected inflammatory genes compared with control HUVECs (dark grey). Data are means of five independent and duplicate experiments.
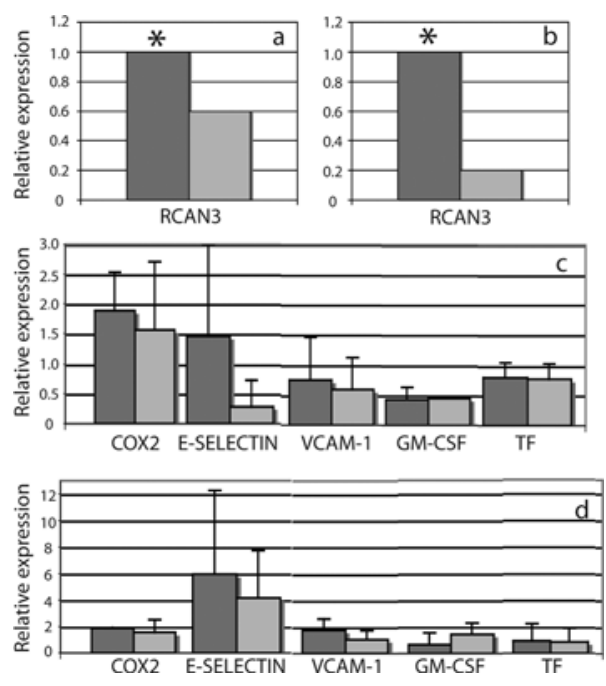

Figure 4. RCAN3 knockdown effect on inflammatory gene expression in HUVECs under stimulated conditions. In a) and b) RCAN3-siRNA (light grey) decrease RCAN3 expression by at least $40 \%$ in VEGF-treated HUVECs (a) and $80 \%$ in PMA-stimulted HUVECs (b) in all experiments performed compared with VEGF or PMA treated cells (dark grey) ( $>>0.05)$. In c) and d) RCAN3-siRNA (light grey) did not significantly alter ( $P>0.05)$ the expression of selected inflammatory genes in VEGF (c) or PMA (d) stimulted HUVECs compared with VEGF or PMA treated cells (dark grey). Data are means of three independent and duplicate experiments.

RCAN3 inhibits HUVEC proliferation. Initial investigations, almost a decade ago, identified a significant induction of RCAN1 in HUVECs in response to VEGF leading to the proposal of a molecular mechanism underlying the regulation of angiogenic and inflammatory genes activated by the $\mathrm{Cn}$ NFAT signaling pathway in endothelial cells. On this basis, it has been demonstrated that RCAN1 (and RCAN2) attenuates proliferation of HUVECs. Since RCAN3 can also interact with, 
and inhibit $\mathrm{Cn}$, we reasoned it could alter the proliferating phenotype of HUVECs. To this end, experiments aiming at determining cell growth, monitored with the Alamar Blue assay, on HUVECs with or without RCAN3 knockdown, and with or without a pro-inflammatory agent (VEGF or PMA) were performed. Thus, while the effects of RCAN1 and RCAN2 were tested only in stimulated HUVECs, the potential effect of RCAN3 was also analysed under basal conditions.

In resting HUVECs, knockdown of RCAN3 led to an average 4.2-fold increase in proliferation (Fig. 2a). Though to a lesser extent, this increase in cell growth was also evident in knockdown of RCAN3 in VEGF-treated cells (with an average of 1.7-fold increase in proliferation). Such an effect was not stimulus specific because it was also evident in PMA-treated cells (with an average of 1.9-fold increase) (Fig. 2b).

The lower degree of effect elicited by the siRCAN3 was likely due to the proliferating activity of both VEGF and PMA, thus partially over-ruling the inhibitory properties of RCNA3, hence masking the impact of its down-regulation by silencing mRNA. In any case, these experiments show a clear role for cellular RCAN3 in inhibiting HUVEC proliferation both in basal and stimulated HUVECs. The latter property is shared by RCAN1 and RCAN2.

With respect to relative importance, it is worth noting that basal RCAN3 levels are much higher than those of RCAN1. Infact RCAN1 is slightly expressed in basal conditions and it can affect cell proliferation only when induced. Thus, it is plausible that between the two proteins, RCAN3 is endowed with a more physiological function, whereas RCAN1 becomes relevant under stress and/or conditions that would induce its gene expression. Further studies are required to fully elucidate the role of RCAN3, and RCAN1, in HUVEC proliferation.

Role of RCAN3 on the expression of inflammatory genes in HUVECs. After demonstrating that RCAN3 inhibits HUVEC proliferation, we sought to investigate whether this ability was associated with a role in inflammation and angiogenesis as is the case for RCAN1 and RCAN2 by evaluating whether RCAN3 modulated the level of expression of some key inflammatory genes. In fact, endothelial cell activation is mediated by several different signals, which result in overlapping yet distinct patterns of gene expression. In the present work, we have taken into account the genes which, on the basis of previous studies, play a pivotal role during inflammation and angiogenesis. Their products are E-selectin, an endothelial cell specific membrane glycoprotein that mediates slow rolling and stable arrest of leukocytes on endothelium during inflammation and that may play a role in angiogenesis (26); VCAM-1, which facilitates slowing of selectin-initiated rolling cells and promotion of firm adhesion (27); COX-2 which converts arachidonic acid to prostaglandin $\mathrm{H}_{2}$ and, in endothelial cells, is induced in response to multiple stimuli (28); GM-CSF, a cytokine that seems to be responsible for the crosstalk between hematopoietic cells and tissue cells during the inflammatory process (29); TF, a transmembrane glycoprotein induced in endothelial cells by various stimulations, that also has a role in inflammation by increasing the pro-inflammatory functions of macrophages and upregulating IL-8 (30).

Quantitative relative RT-PCR was also performed to evaluate the relative expression of RCAN3 and the inflammatory genes (COX-2, E-selectin, VCAM-1, GM-CSF and TF) in RCAN3-siRNA-transfected HUVECs. In basal conditions HUVEC transfection with $R C A N 3$-siRNA reduced $R C A N 3$ expression by at least $55 \%$, while alteration of COX-2, E-selectin, VCAM-1, GM-CSF gene expression is not statistically significant (Fig. 3). Reductions of RCAN3 expression of at least 40 and $80 \%$ were measured in HUVECs treated with RCAN3-siRNA and stimulated with VEGF or with the PMA/IO combination, respectively, compare to those stimulated with VEGF or with the PMA/IO combination. As well as in basal conditions, in stimulated HUVECs, no statistically significant alterations in inflammatory gene expression were evident (Fig. 4). No significant decrease in RCAN3 expression was seen in HUVECs transfected with SCRAM-siRNA compared with the targeting siRNA (data not shown).

We assume that the ability of RCAN3 to reduce proliferation is independent from the inflammatory or angiogenic processes in HUVECs. The strong function of RCAN1 could also be confirmed by its strong activation by VEGF (the strongest among thousands of genes) in more than one experiment. RCAN members share the ability to bind and inhibit $\mathrm{Cn}$, but at the same time they are three different genes and proteins with other specific functions, as can be seen from several of their other specific binding proteins, such as, the human cardiac troponin I (TNNI3) for RCAN3 (31).

In conclusion, we have shown for the first time an anomalous expression profile of the RCAN3 isoform specific to HUVECs and a role for RCAN3 in inhibiting HUVEC proliferation, both in basal and VEGF or PMA stimulated conditions, independently from the inflammatory and angiogenic processes.

\section{Acknowledgments}

This work was funded by a grant from 'Fondazione Carisbo', Bologna, Italy and by an MIUR ex $60 \%$ grant to S.C.. D.C., L.V.N. and M.P. are supported by the William Harvey Research Foundation (BPHG1D7R). We are grateful to Gabriella Mattei for her excellent technical assistance with automated sequencing.

\section{References}

1. Strippoli P, Lenzi L, Petrini M, Carinci P and Zannotti M: A new gene family including DSCR1 (Down Syndrome Candidate Region 1) and ZAKI-4: characterization from yeast to human and identification of DSCR1-like 2, a novel human member (DSCR1L2). Genomics 64: 252-263, 2000.

2. Davies KJA, Ermak G, Rothermel BA, et al: Renaming the DSCR1/Adapt78 gene family as RCAN - regulators of calcineurin. FASEB J 21: 3023-3028, 2007.

3. Fuentes JJ, Pritchard MA, Planas AM, Bosch A, Ferrer I and Estivill X: A new human gene from the Down syndrome critical region encodes a proline-rich protein highly expressed in fetal brain and heart. Hum Mol Genet 4: 1935-1944, 1995.

4. Miyazaki T, Kanou Y, Murata Y, Ohmori S, Niwa T, Maeda K, Yamamura $\mathrm{H}$ and Seo $\mathrm{H}$ : Molecular cloning of a novel thyroid hormoneresponsive gene, ZAKI-4, in human skin fibroblasts. J Biol Chem 271: 14567-14571, 1996. 
5. Facchin F, Canaider S, Vitale L, Frabetti F, Griffoni C, Lenzi L, Casadei R and Strippoli P: Identification and analysis of human RCAN3 (DSCR1L2) mRNA and protein isoforms. Gene 407: 159-168, 2008

6. Strippoli P, D'Addabbo P, Lenzi L, Giannone S, Canaider S, Casadei R, Vitale L, Carinci P and Zannotti M: Segmental paralogy in the human genome: a largescale triplication on $1 \mathrm{p}$, 6p, and 21. Mamm Genome 13: 456-462, 2002.

7. Mulero MA, Aubareda A, Schluter A and Perez-Riba M: RCAN3, a novel calcineurin inhibitor that down-regulates NFATdependent cytokine gene expression. Biochim Biophys Acta 1773: 330-341, 2007.

8. Fuentes JJ, Genescà L, Kingsbury TJ, Cunningham KW, Pérez-Riba M, Estivill X and de la Luna S: DSCR1, overexpressed inDown syndrome, is an inhibitor of calcineurin-mediated signaling pathways. Hum Mol Genet 9: 1681-1690, 2000.

9. Rothermel B, Vega RB, Yang J, Wu H, Bassel-Duby R and Williams RS: A protein encoded within the Down syndrome critical region is enriched in striated muscles and inhibits calcineurin signaling. J Biol Chem 275: 8719-8725, 2000.

10. Aubareda A, Mulero MC and Perez-Riba M: Functional characterization of the calcipressin 1 motif that suppresses calcineurin-mediated NFAT-dependent cytokine gene expression in human T cells. Cell Signal 18: 1430-1438, 2006.

11. Molkentin JD, Lu JR, Antos CL, Markham B, Richardson J, Robbins J, Grant SR and Olson EN: A calcineurin-dependent transcriptional pathway for cardiac hypertrophy. Cell 93: 215-228, 1998.

12. Bueno OF, Lips DJ, Kaiser RA, et al: Calcineurin A gene targeting predisposes the myocardium to acute ischemiainduced apoptosis and dysfunction. Circ Res 94: 91-99, 2004.

13. Aramburu J, Rao A and Klee CB: Calcineurin: from structure to function. Curr Top Cell Regul 36: 237-295, 2000.

14. Parsons SA, Millay DP, Wilkins BJ, et al: Genetic loss of calcineurin blocks mechanical overload-induced skeletal muscle fiber type switching but not hypertrophy. J Biol Chem 279: 26192-26200, 2004.

15. Zeng H, Chattarji S, Barbarosie M, et al: Forebrain-specific calcineurin knockout selectively impairs bidirectional synaptic plasticity and working/episodic-like memory. Cell 107: 617-629, 2001.

16. Lee JI and Ahnn J: Calcineurin in animal behaviour. Mol Cell 17: 390-396, 2004

17. Abe M and Sato Y: cDNA microarray analysis of the gene expression profile of VEGF-activated human umbilical vein endothelial cells. Angiogenesis 4: 289-298, 2001.

18. Liu D, Gia H, Holmes DI, Stannard A and Zachary I: Vascular endothelial growth factor-regulated gene expression in endothelial cells: KDR-mediated induction of Egr3 and the related nuclear receptors Nur77, Nurr1, and Nor1. Arterioscler Thromb Vasc Biol 23: 2002-2007, 2003
19. Yao Y-G and Duh EJ: VEGF selectively induces Down syndrome critical region 1 gene expression in endothelial cells: a mechanism for feedback regulation of angiogenesis? Biochem Bioph Res Commun 321: 648-656, 2004.

20. Minami T, Horiuchi K, Miura M, et al: Vascular endothelial growth factor- and thrombin-induced termination factor, Down syndrome critical region-1, attenuates endothelial cell proliferation and angiogenesis. J Biol Chem 279: 50537-50554, 2004.

21. Hesser BA, Liang XH, Camenisch G, et al: Down syndrome critical region protein 1 (DSCR1), a novel VEGF target gene that regulates expression of inflammatory markers on activated endothelial cells. Blood 104: 149-158, 2004.

22. Gollogly LK, Ryeom SW and Yoon SS: Down syndrome candidate region 1-like 1 (DSCR1-L1) mimics inhibitory effects of DSCR1 on calcineurin signaling in endothelial cells and inhibits angiogenesis. J Surg Res 142: 129-136, 2007.

23. Spisni E, Griffoni C, Santi S, et al: Colocalization prostacyclin (PGI2) synthase - caveolin-1 in endothelial cells and new roles for PGI2 in angiogenesis. Exp Cell Res 266: 31-43, 2001.

24. Al-Nasiry S, Geusens N, Hanssens M, Luyten C and Pijnenborg R: The use of Alamar Blue assay for quantitative analysis of viability, migration and invasion of choriocarcinoma cells. Hum Reprod 22: 1304-1309, 2007.

25. Davuluri RV, Suzuki Y, Sugano S, Plass C and Huang TH: The functional consequences of alternative promoter use in mammalian genomes. Trends Genet 24: 167-177, 2008.

26. Yu Y, Moulton KS, Khan MK, Vineberg S, et al: E-selectin is required for the antiangiogenic activity of endostatin. Proc Natl Acad Sci USA 101: 8005-8010, 2004.

27. Barthel SR, Gavino JD, Descheny L and Dimitroff CJ: Targeting selectins and selectin ligands in inflammation and cancer. Expert Opin Ther Targets 11: 1473-1491, 2007.

28. Hernández GL, Volpert OV, Iñiguez MA, et al: Selective inhibition of vascular endothelial growth factor-mediated angiogenesis by cyclosporin A: roles of the nuclear factor of activated T cells and cyclooxygenase 2. J Exp Med 193: 607-620, 2001.

29. Hamilton JA: GM-CSF in inflammation and autoimmunity. Trends Immunol 23: 403-408, 2002.

30. Daubie V, Pochet R, Houard S and Philippart P: Tissue factor: a mini-review. J Tissue Eng Regen Med 1: 161-169, 2007.

31. Canaider S, Facchin F, Griffoni C, Casadei R, Vitale L, Lenzi L, Frabetti F, D'Addabbo P, Carinci P, Zannotti M and Strippoli P: Proteins encoded by human Down syndrome critical region gene 1-like 2 (DSCR1L2) mRNA and by a novel DSCR1L2 mRNA isoform interact with cardiac troponin I (TNNI3). Gene 372: 128-136, 2006. 